\title{
Development of an Automotive Liquid Waste Management System for the BSU-CIT Automotive Technology Department
}

\author{
Warlito Galita, Charlie Cano \\ College of Industrial Technology, Bulacan State University, Malolos, Philippines \\ Email: chloky23@yahoo.com
}

Received 19 March 2015; accepted 3 April 2015; published 7 April 2015

Copyright (C) 2015 by authors and OALib.

This work is licensed under the Creative Commons Attribution International License (CC BY). http://creativecommons.org/licenses/by/4.0/

(c) (i) Open Access

\section{Abstract}

This action research aimed to identify the various problems and issues arising from the day-to-day operations of the automotive repair shop in terms of proper automotive liquid waste management and from these problems, to develop an Automotive Liquid Waste Management System for the BSU-CIT Automotive Technology Department. The respondents of this study were the $\mathbf{7 7}$ faculty members and selected students from the College of Industrial Technology Automotive Technology in the BSU Main Campus for the school year of 2013-2014. The main survey instrument used in this study is the standardized Survey Questionnaire on Automotive Liquid Waste Management of www.spokanewastewater.org. The said instrument was slightly modified to fit the research locale and conditions of the study. Based on the results of this study, the AT department services an average of 3 vehicles per day, with usual operating hours of 4 hours a day. It also commonly offers the following services namely: oil change, brake and engine repair. The most common type of equipment found in the AT department is the vehicle lift, part washer and oil drum rack. In addition, the most common type of liquid automotive waste products generated is the used motor oil (15 - 20 liters) and the used brake fluid (4 liters and below). Finally, the respondents all "Agree" that there is a need to recycle used oil and that there is also a procedure in handling and disposing liquid automotive waste. On the basis of the foregoing significant findings and conclusions of this study, the following recommendations are offered: 1) the CIT should sponsor orientation seminars regarding liquid automotive waste for both students and teachers in the AT Department; 2) the teachers continue to strive to continuously look for creative ways to minimize and recycle various automotive liquid wastes; 3 ) the teachers are encouraged to manifest favorable values in caring for the environment to their students; and 4) the school administration may also consider the implementation of the proposed liquid automotive waste manual to further improve the current practices in the AT Department.

\section{Keywords}

Automotive Liquid Waste, CIT, Bulacan State University, BSU

How to cite this paper: Galita, W. and Cano, C. (2015) Development of an Automotive Liquid Waste Management System for the BSU-CIT Automotive Technology Department. Open Access Library Journal, 2: e1429.

http://dx.doi.org/10.4236/oalib.1101429 


\section{Introduction}

Air pollution is becoming a major problem in urban centers as well as rural areas near industrial sites, commercial centers, or transportation hubs. Air pollutants have no boundaries; some can travel hundreds of kilometers and result in damage elsewhere. It is therefore important not only to monitor the quality of air in these threatened areas, but also to identify the sources of various substances that pollute our air so that appropriate measures can be implemented to eliminate or reduce them significantly at their sources.

In this light, Department of Environment and Natural Resources (DENR) conducted a national emissions inventory of air pollution sources in 1990. Updates to the inventory were made in 2001-2004 and then in 2006. The Philippine Clean Air Act of 1999 (Republic Act 8749) requires an emissions inventory to be conducted once every three years. The emissions inventory includes criteria pollutants such as particulate matter (PM), sulfur oxides, nitrogen oxides, carbon monoxide, and volatile organic compounds. Based on the 2006 National Emissions Inventory, the transport sector is the major source of air pollution in many regions of the country. It was estimated that $65 \%$ of the pollutants came from automobile sources [1].

However, major legislation only sets the goal, but does not pave the road to it. There appears to be a gap between science and technology, and it can only be bridged by technical know-how in the field of Automotive Technology. Automotive Technology plays a very important role in reducing pollution by ensuring that vehicles are operating efficiently and by extending vehicle life through preventive routine maintenance. However, dayto-day operations of these automotive shops and work areas generate various forms of waste by-products in terms of smoke, harmful emissions, toxic liquid wastes and the like.

Minimizing the environmental impact of the day-to-day operations can be challenging, but successful automotive waste management depends on the stakeholders working together to keep the work environment clean. They must recognize the need to establish and practice spill prevention, clean up spills appropriately, and properly manage and dispose of these liquid hazardous wastes. Essentially, this action research identified the various problems and issues arising from the day-to-day operations of these automotive repair shops in terms of proper automotive liquid waste management and from these problems, it is to develop an Automotive Liquid Waste Management System for the BSU-CIT Automotive Technology Department.

\section{The Research Problem}

The general problem of the study is: what is the current protocol of the Bulacan State University in handling and disposing automotive liquid waste?

1) How may the operation of the automotive technology department be described in terms of...

a) Average number of vehicles serviced per day?

b) Hours of operation?

c) Type of vehicle services rendered?

d) Major equipment used at the facility?

2) How may the most common types of liquid automotive waste products be described in terms of the amount generated?

3) What are the current practices being employed by the BSU Automotive Department in handling and disposing their liquid waste products?

4) What Automotive Liquid Waste Management System for a Clean Environment may be proposed and implemented?

\section{Methodology}

The conceptual framework of the study is shown in Figure 1. The paradigm clearly shows that the central concern of the study is the development of an effective liquid automotive waste management system in the Bulacan State University-CIT Automotive Department. The conceptual model of the study followed the Input-ProcessOutput (IPO) format which consists of three (3) frames; the first frame shows the inputs of the study, while the 
Input

Current status of Liquid Automotive Waste in the BulSU-CIT (Automotive Department)

Current Practices in the handling and disposal of liquid automotive waste

International and Philippine Laws
Process

Data gathering using standardized instrument

Analysis of Data in e-waste generation

Comments, and suggestions on some questions included in the survey questionnaire
Output

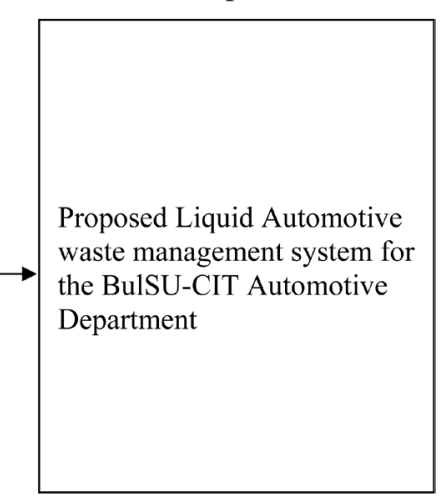

Figure 1. The conceptual paradigm of the study.

second frame presents the processes involved in the conduct of the study and the third frame presents the output, which is the proposed framework for an effective liquid automotive waste management system.

The first frame presents the inputs which are the information gathered from laws, Current status of automotive waste in the BulSU-CIT Automotive Department, Current Practices in the handling and disposal of these wastes, as well as International and Philippine Laws as well as informal and formal interviews from stakeholders that will be used as the main source in the preparation of the proposed liquid automotive waste management system. The positive and negative comments of the stakeholders on how liquid automotive waste is handled and disposed of will also be considered as valuable inputs of this study.

The second frame presents the process of how the data in terms of automotive waste in the BSU will be evaluated. Comprehensive data gathering using standardized instrument, analysis of data in waste generation and comments, and suggestions on some questions included in the survey questionnaire. The last frame is the output of the study, which is the enhanced level of awareness of stakeholders regarding liquid automotive waste, which will in turn produce an improved automotive waste management in the BSU-CIT Automotive Department.

The action research at hand is a linear type research approach. The research passes through the steps of questioning a particular issue, definition of problems through reflecting and investigating the issue, developing an action plan, conduction of the action, questioning, reflection, and re-definition of the problem and kicks-off to the next cycle which is the dissemination of research results [2].

The major instrument used in the data gathering is the standardized Survey Questionnaire on Automotive Liquid Waste Management [3]. The rating instruments were supplemented with unstructured interviews and ocular observations in order to validate their responses. Since the study utilized a standardized instrument, the researcher sought permission from his adviser before administering the questionnaire. In addition, each item of the questionnaire was thoroughly checked to ascertain whether the statements are applicable to the current setting and conditions of the study. The respondents of this study were the 77 faculty members and selected students from the College of Industrial Technology Automotive Technology in the BSU Main Campus for the school year 2013-2014.

\section{Results and Discussion}

This chapter presents, analyzes and interprets the data gathered from the respondents to assess their level of awareness regarding liquid automotive waste in the Bulacan State University College of Industrial Technology (BSU-CIT) Automotive Technology Department for the school year 2013-2014. It also looked into the possible solutions wherein the effective and efficient automotive liquid waste management may be put forward.

\subsection{Part I. Automotive Technology Department Operation Description}

Table 1 shows the number of vehicles serviced per day in the Automotive Technology (AT) Department. A quick glance at the table reveals that the most common number of vehicles serviced per day is 3 vehicles (39\% or $51 \%)$. This is followed by 2 vehicles serviced per day (17\% or $22 \%)$ and 5 vehicles per day ( $8 \%$ or $10 \%)$. The overall mean of 3.3 simply shows that the average number of vehicles serviced per day is 3 . This is indicative of 
Table 1. Frequency distribution of the average number of vehicle serviced per day.

\begin{tabular}{cccc}
\hline Number of Vehicles Serviced Daily & Frequency & Percent \\
\hline 1 & 4 & $5 \%$ \\
2 & 17 & $22 \%$ \\
3 & 39 & $51 \%$ \\
4 & 3 & $4 \%$ \\
6 & 8 & $10 \%$ \\
9 & 2 & $3 \%$ \\
Total & 4 & $5 \%$ \\
Mean & 77 & $\mathbf{1 0 0}$ \\
\hline
\end{tabular}

the fact that the number of vehicles serviced may vary from time to time, although the average number would be around 3 vehicles.

Table 2 shows the distribution of hours of operation of services in the AT Department. The tabular data clearly shows that twenty-three (23) respondents representing $30 \%$ of the whole said that the most frequent number of hour of operation is 3 hours. This is followed by fifteen (15) respondents representing $20 \%$ saying 4 hours and 12 respondents saying 6 hours. In sum, the overall mean of 4.23 reveals that the average number of hours of shop operation is 4 hours.

Given in Table 3 is the distribution of the type of vehicle services offered in the AT Department. Services offered ranged from oil change, engine repair, car wash, auto detailing, among others. The tabular values show that among these wide variety of services offered in the Automotive Technology Department, oil change was ranked as number 1 , followed by engine repair as well as brake repair (2.5) and transmission repair (3). These findings reveal that these services are the most commonly availed not only in the department but also in automotive repair shops outside the University simply because these services represent the most common type of preventive maintenance procedures usually performed on vehicles, whether they are brand new or second hand cars. These findings also implies that based on these services, one can only surmise the most common automotive waste being generated in the AT Department is used oil and used brake fluids.

Table 4 shows the distribution of major equipment being used in the AT Department. A quick perusal of the tabular values show that the vehicle lift is ranked number 1 (59), followed by parts washer (52) and oil drum rack (47). This is followed by mobile drain rigs (28) and used oil rag bins (27). These results reveal that the AT department have the most common equipment needed in the proper operation of an automotive repair shops.

\subsection{Part II. Common Types of Liquid Automotive Waste Products Generated}

This part presents the common types of liquid automotive waste products generated in the AT Department. For purposes of simplicity, since the most common type of automotive services offered in the AT Department is oil change, engine repair and brake repair, the study focused on the two most common liquid automotive wastes produced.

Presented in Table 5 is the distribution of liquid automotive waste in terms of used motor oil. The amount of motor oil produced is bracketed as follows; 1) 21 liters and above; 2) 15 - 20 liters; 3) 10 - 14 liters; 4) 5 - 9 liters and 5) 4 liters and below.

The tabular values reveal that thirty-five (35) respondents representing $46 \%$ of the whole said that on the average, the AT Department produces around 15 - 20 liters of used motor oil per month. This is followed by 19 respondents (24\%) and 10 respondents (13\%) producing 10 - 14 liters and 21 liters and above of used oil per month, respectively.

These findings imply that the AT Department shop produces considerable amount of used motor oil that is enough to warrant an effective management of automotive liquid waste. This finding is critical because the automotive repair industry is composed of three primary segments: automotive repair shops; new car dealerships; and diesel engine repair shops. These three segments produce significant solvent wastes, aqueous wastes, and 
Table 2. Frequency distribution of the hours of operation of services.

\begin{tabular}{ccc}
\hline Average Number of Hours & Frequency & Percent \\
\hline 1 & 4 & $5 \%$ \\
2 & 9 & $12 \%$ \\
3 & 23 & $30 \%$ \\
4 & 15 & $20 \%$ \\
5 & 3 & $4 \%$ \\
6 & 12 & $16 \%$ \\
8 & 11 & $14 \%$ \\
Total & 77 & $\mathbf{1 0 0}$ \\
Mean & & $\mathbf{4 . 2 3}$ \\
\hline
\end{tabular}

Table 3. Frequency distribution on the type of vehicle services offered.

\begin{tabular}{cccc}
\hline Services & Frequency & Rank \\
\hline Oil Change & 69 & 1 \\
Engine Repair & 65 & 2.5 \\
Car Washing & 44 & 5 & 2.5 \\
Brake Repair & 65 & 8 & 7 \\
Auto Detailing & 25 & 4 \\
Body Work/Painting & 34 & 9 \\
Tire Repair & 47 & 3 \\
Large Vehicle & 20 & 6 \\
Transmission Repair & 49 & 10 \\
Radiator Services & 41 & 3 \\
Other Services & 18 & & \\
\hline
\end{tabular}

Table 4. Frequency distribution of major equipment in the AT department.

\begin{tabular}{ccc}
\hline List of Major Equipment & Frequency & Rank \\
\hline Vehicle Lift & 59 & 1 \\
Solvent Cabinet & 20 & 8 \\
Mobile Drain Rigs & 28 & 4 \\
Parts Washer & 51 & 2 \\
Paint Cabinet & 26 & 9 \\
Paint Booth & 16 & 3 \\
Oil Drum Rack & 47 & 5 \\
Used Oil Rag Bins & 27 & 7 \\
Refrigerant Equipment & 25 & 10 \\
Others & 14 & \\
\hline
\end{tabular}

sludges which require disposal as hazardous waste. Of small quantity generators of hazardous waste located in the United States, automotive repair leads in number of generators and in quantity of total waste produced [4].

On the other hand, Table 6 shows the distribution of automotive liquid waste in terms of used brake fluid. 
Table 5. Frequency distribution of liquid automotive waste produced monthly.

\begin{tabular}{cccc}
\hline Used Motor Oil & Frequency & Percent & Rank \\
\hline 21 liters and above & 10 & $13 \%$ & 3 \\
$15-20$ liters & 35 & $46 \%$ & 1 \\
$10-14$ liters & 19 & $24 \%$ & 4 \\
$5-9$ liters & 7 & $8 \%$ & 5 \\
4 liters - below & 6 & $\mathbf{1 0 0 \%}$ & \\
Total & $\mathbf{7 7}$ & & \\
\hline
\end{tabular}

Table 6. Frequency distribution of liquid automotive waste.

\begin{tabular}{cccc}
\hline Used Brake Fluid & Frequency & Percent & Rank \\
\hline 21 liters and above & 3 & $4 \%$ & 5 \\
$15-20$ liters & 11 & $14 \%$ & 4 \\
$10-14$ liters & 18 & $23 \%$ & 2 \\
$5-9$ liters & 15 & $39 \%$ & 1 \\
4 liters - below & 30 & $\mathbf{1 0 0 \%}$ & 3 \\
Total & $\mathbf{7 7}$ & & \\
\hline
\end{tabular}

The tabular values reveal that 30 respondents (39\%) felt that the AT Department produces 4 liters and below of used brake fluid. This is followed by 18 respondents (23\%) and 15 respondents (20\%) who felt that the used brake fluid produced is 10 - 14 liters and 5 - 9 liters, respectively. These findings imply that unlike used oil, used brake fluids produced in the AT Department is not that voluminous. However, a sound liquid automotive waste is still needed in the management of wastes in the AT Department.

Numerous automotive repair facilities routinely produces liquid automotive waste like brake fluids, paint removers, waste acid, alkaline cleaning fluids, and generate a variety of waste materials that may be waste battery acid. Corrosive wastes have an EPA considered hazardous waste. These waste materials include used motor oil, solvents, parts washer solutions, paints, antifreeze, used batteries, automotive fluids and a host of others. If these liquid waste materials are not handled correctly, they can harm people and the environment when thrown away irresponsibly.

\subsection{Part III. Current Practices in Handling and Disposing Liquid Automotive Waste}

Shown in Table 7 are the descriptive measures of the current practices in handling and disposing liquid automotive waste in the AT department.

A quick perusal of the tabular values show that item number 2, which is "Do you agree that used oil should be recycled" was given the highest mean rating of 4.11, interpreted as "Agree". This implies that the respondents believe that used motor oil should be reused, which in turn will minimize generated waste. This is followed by item number 1, which is "Do you agree that there is a current procedure of handling and disposing liquid automotive waste in the BulSU?" garnered the highest mean rating of 3.87, interpreted as "Agree”.

This finding is indicative of the fact that the respondents felt that there is a current protocol with regards to the management of liquid automotive waste. This is followed by the item referring to recycling of used motor oil as fluid for engine mock-ups/trainers, which obtained a mean of 3.70, interpreted as "Agree". This finding shows that the respondents are in agreement that one way of recycling used oil is to reuse them as lubricants for the engine trainers in their respective shops.

On the other hand, item number 5.4, which refers to the disposal of used oil by pouring it down street drains obtained the lowest mean rating of 2.08, interpreted as "Less Agree". This shows that the respondents are fully aware that this type of automotive liquid waste disposal is not proper and that explains its low mean rating. This is followed by the disposal of used oil by placing it in the garbage at home, as evidenced by the mean rating of 
Table 7. Descriptive measure of the current practices on disposing liquid automotive waste.

\begin{tabular}{|c|c|c|c|c|c|c|c|}
\hline \multirow[b]{2}{*}{ Statements } & \multicolumn{5}{|c|}{ Frequency } & \multirow[b]{2}{*}{ Mean } & \multirow[b]{2}{*}{$\begin{array}{c}\text { Verbal } \\
\text { Interpretation }\end{array}$} \\
\hline & $\begin{array}{c}\text { Strongly } \\
\text { Agree } \\
5\end{array}$ & $\begin{array}{l}\text { Agree } \\
4\end{array}$ & $\begin{array}{c}\text { Moderately } \\
\text { Agree } \\
3\end{array}$ & $\begin{array}{l}\text { Disagree } \\
2\end{array}$ & $\begin{array}{c}\text { Strongly } \\
\text { Disagree } \\
1\end{array}$ & & \\
\hline $\begin{array}{l}\text { 1. Do you agree that there is a } \\
\text { current procedure of handling } \\
\text { and disposal liquid aumotive } \\
\text { waste in BulSu? }\end{array}$ & 26 & 19 & 29 & 2 & 1 & 3.87 & Agree \\
\hline $\begin{array}{l}\text { 2. Do you agree that used oil } \\
\text { should be recycle? }\end{array}$ & 27 & 35 & 13 & 1 & 1 & 4.11 & Agree \\
\hline $\begin{array}{l}\text { 3. In what ways should used } \\
\text { oil be recycled? } \\
3.1 \text { As lubricant }\end{array}$ & 10 & 37 & 25 & 4 & 1 & 3.66 & Agree \\
\hline $\begin{array}{l}\text { 3.2 As spent oil/Fluid for } \\
\text { engine mock-up/trainer }\end{array}$ & 11 & 36 & 27 & 2 & 1 & 3.70 & Agree \\
\hline $\begin{array}{l}\text { 4. Do you agree that used oil } \\
\text { should be disposed of? }\end{array}$ & 7 & 20 & 23 & 24 & 3 & 3.05 & $\begin{array}{l}\text { Moderately } \\
\text { Agree }\end{array}$ \\
\hline $\begin{array}{l}\text { 5. How should used oil be } \\
\text { disposed of? } \\
5.1 \text { Store it at home/work }\end{array}$ & 8 & 17 & 8 & 25 & 19 & 2.61 & $\begin{array}{l}\text { Moderately } \\
\text { Agree }\end{array}$ \\
\hline $\begin{array}{l}5.2 \text { Place it in the garbage } \\
\text { at home }\end{array}$ & 10 & 8 & 11 & 24 & 24 & 2.43 & $\begin{array}{l}\text { Moderately } \\
\text { Agree }\end{array}$ \\
\hline $\begin{array}{l}5.3 \text { Place it in the dumpster } \\
\text { at some other location }\end{array}$ & 8 & 15 & 18 & 19 & 17 & 2.71 & $\begin{array}{l}\text { Moderately } \\
\text { Agree }\end{array}$ \\
\hline $\begin{array}{l}\text { 5.4 Pour it down street } \\
\text { drains }\end{array}$ & 5 & 9 & 13 & 15 & 30 & 2.08 & Less Agree \\
\hline
\end{tabular}

2.43, interpreted as "Moderately Agree". These results show that the respondents are well informed regarding the proper disposal methods of used oil.

This is important since waste was, is and will always be the problem until and unless better ideas are introduced for its management. Since life standards of people are growing and so is the production of waste. Even thought are so many policies going through the waste management the system is lacking the success to minimize it to the lowest. Different principles have been applied in the field of waste management, but 3Rs i.e. reducing, reusing and recycling are deemed the best practices for waste management.

\section{Conclusions}

On the basis of the significant findings, the following conclusions are drawn:

1) The AT department services an average of 3 vehicles per day, with usual operating hours of 4 hours a day. It also commonly offers the following services namely: oil change, brake and engine repair. The most common type of equipment found in the AT department is the vehicle lift, part washer and oil drum rack.

2) The most common type of liquid automotive waste products generated in the AT Department is the used motor oil (15 - 20 liters) and the used brake fluid (4 liters and below).

3) The respondents all "Agree" that there is a need to recycle used oil and that there is also a procedure in handling and disposing liquid automotive waste. 


\section{Recommendations}

On the basis of the significant findings and conclusions of this study, the following are the recommendations:

1) The school administration should sponsor seminars regarding liquid automotive waste for both students and teachers in the AT Department.

2) The teachers continue to strive to continuously look for other creative ways to minimize and recycle various automotive liquid wastes. This will enable them to be engaged in research, thus upgrading their professional qualifications to keep them abreast with the development of the times in the area of automotive technologies.

3) Both the teachers are encouraged to manifest favorable values in caring for the environment to their students.

4) The school administration may also consider the implementation of the proposed liquid automotive waste manual to further improve the current practices in the AT Department.

5) For future researchers, it is recommended that follow-up researches on the following related areas/topics should be undertaken:

a) The Effectiveness of the Proposed Liquid Automotive Waste Manual in the Bulacan State University-College of Industrial Technology Automotive Department.

b) Liquid Automotive Waste Management Practices at the Different Automotive Repair Shops in the City of Malolos.

\section{References}

[1] ASEAN (2009) German Technical Cooperation Clean Air for Smaller Cities in the ASEAN Region. http://cleanairinitiative.org/portal/system/files/FINAL_Philippine_Country_Profile_10Jan10.pdf

[2] Balcazar, F.E., Taylor, R.R., Kielhofner, G.W., Tamley, K., Benziger, T., Carlin, N., et al. (2004) Participatory Action Research: General Principles and a Study with a Chronic Health Condition. In: Jason, L.A., Keys, C.B., Suarez-Balcazar, Y., Taylor, R.R., Davis, M.I., Durlak, J.A. and Isenberg, D.H., Eds., Participatory Community Research, Theories and Methods in Action, American Psychological Association, Washington DC, 17-35. http://dx.doi.org/10.1037/10726-001

[3] Survey Questionnaire on Automotive Liquid Waste Management (2014). Www.spokanewastewater.org

[4] USEPA (1985) Survey of Small Quantity Generators. US Environmental Protection Agency Office of Solid Waste and Emergency Response, Washington DC. 